\title{
Diagnosis of asthma in adults
}

\author{
Alan G. Kaplan MD, Meyer S. Balter MD, Alan D. Bell MD, Harold Kim MD, R. Andrew Mclvor MD MSc
}

\section{The case}

Sara is a 41-year-old secretary in an autobody shop who comes to see you for evaluation of intermittent episodes of wheeze and shortness of breath that have progressed over the past 2 years. She feels that she has more "colds" than her workplace colleague, each of which lasts for 2-3 weeks, with persistent cough and dyspnea. She had wheezing and allergy symptoms in childhood, and her mother and 1 cousin have confirmed asthma. Over the past 6 months, she has noticed that because of her dyspnea, she is unable to keep up with her partner when they go salsa dancing. She is otherwise well and is taking no medications. She smokes a half package of cigarettes daily and has done so for 20 years.

Sara states that she has never received a diagnosis of asthma. However, because she often gets a stuffy nose, she has wondered if she has allergies. Her mother has told her that she had eczema as a baby, and she remembers having itchy, red rashes when she was younger. She wakes up a couple of times a week because of coughing, but she can generally get back to sleep after she coughs up some phlegm.

$\mathrm{T}$ he first step in managing asthma is to make the correct diagnosis. Asthma may mimic other common conditions and may be either overdiagnosed ${ }^{1}$ or underdiagnosed. ${ }^{2}$ After an appropriate history has been obtained and a physical examination performed, the recommended diagnostic testing methods include spirometry (preferred), serial peak flow measurements and provocational challenges.

Asthma is the most common chronic respiratory disease in Canada, affecting about 2.2 million adults and 0.8 million children..$^{3-5}$ Poor asthma control imposes a significant burden on the health care system, ${ }^{6,7}$ with the annual direct and indirect costs estimated at between \$504 million and \$648 million in Canada. ${ }^{8}$ However, despite the significant expenditure of health care resources on people with asthma, as well as decades of improvements in diagnosis and treatment and regular updates of evidence-based clinical practice guidelines, asthma control at the population level remains suboptimal. ${ }^{6,7}$

Canadian guidelines for the diagnosis and treatment of asthma have existed since 1989 and were most recently updated in 2003. In this series, we are using case-based examples to highlight recent changes in recommendations for asthma management and to highlight practical aspects of diagnosis and treatment. The case used here focuses on the diagnosis of asthma in adults.

\section{Key points}

- A clinical diagnosis of asthma should be prompted by intermittent symptoms of breathlessness, wheezing, cough, sputum or chest tightness.

- Measurements of lung function by spirometry, before and after administration of a $\beta_{2}$-agonist, should be used to confirm the clinical diagnosis of asthma.

- Occupational asthma should be considered in all cases of new-onset asthma in adults.

- Challenge testing is most useful to exclude a diagnosis of asthma.

The presence of certain key symptoms may suggest the presence of asthma, but can also result from airway inflammation alone, from chronic rather than reversible airflow limitation, or from other respiratory and nonrespiratory conditions. Moreover, asthma symptoms correlate poorly with abnormalities of lung function ${ }^{9}$ and airway inflammation, ${ }^{10,11}$ and thus in isolation may suggest a less severe form of the disease than is actually present. Although many clinicians diagnose asthma on the basis of a trial of therapy, objective measurements are necessary to confirm the clinical diagnosis. Validated questionnaires may be an option in settings where objective testing is unavailable. ${ }^{12}$

Asthma is an inflammatory disease ${ }^{13}$ associated with symptoms resulting from abnormalities of airway function, in particular wide, short-term variations in airflow resistance in the intrapulmonary airways. Thus, a conclusive diagnosis of asthma is based on tests designed to detect rapid changes in the forced expiratory volume in 1 second $\left(\mathrm{FEV}_{1}\right)$ or peak expiratory flow. Although this review focuses particularly on diagnosis, these tests can also be used to assess asthma control and as an aid in optimizing chronic therapy.

The chronic inflammation of asthma is associated with airway hyperresponsiveness that leads to recurrent symptoms, yet lung function may nevertheless remain normal. Identification of airway hyperresponsiveness thus has clinical value, particularly in the diagnosis of asthma in people with normal

From the Department of Family Practice (Kaplan) and the Department of Medicine (Balter), University of Toronto; the Department of Family Medicine (Bell), Humber River Regional Hospital, Toronto, Ont.; the Department of Medicine (Kim), University of Western Ontario, London, Ont.; the Firestone Institute for Respiratory Health (Mclvor), St. Joseph's Healthcare; and the Department of Medicine (Mclvor), McMaster University, Hamilton, Ont.

Cite as CMAJ 2009. DOI:10.1503/cmaj.080006 
spirometry results or with symptoms uncharacteristic of asthma. Airway hyperresponsiveness is usually measured using direct stimuli, such as methacholine or histamine, that act by stimulating specific receptors on the bronchial smooth muscle to cause contraction and narrowing of the airways.

The inflammation associated with asthma is characteristically eosinophilic. Measurement of sputum eosinophilia has been proposed for clinical use in the diagnosis of asthma. However, some patients with this condition have neutrophilic inflammation, whereas, conversely, some patients without asthma have eosinophilic inflammation.

\section{Sources of information}

We identified studies for potential inclusion in this literature review using several search strategies. The main source of studies was the "Asthma and Wheez*" register of the Cochrane Airways Group, which was originally created through a comprehensive search of EMBASE, MEDLINE and CINAHL. We searched all of the register's original research studies and reviews using the following terms: "diagnos*" or "sensitiv*" or "test*" or "challenge" or "examination" or "accuracy." The Asthma and Wheez* register includes studies published in foreign languages. The current

Table 1: Recommendation grades and levels of evidence for specific clinical actions*

\begin{tabular}{|c|c|}
\hline Grade or levelt & Description \\
\hline \multicolumn{2}{|c|}{$\begin{array}{l}\text { Recommendation } \\
\text { grade }\end{array}$} \\
\hline A & There is good evidence to recommend the clinical action. \\
\hline B & There is fair evidence to recommend the clinical action. \\
\hline C & $\begin{array}{l}\text { Existing evidence is conflicting and does not allow a } \\
\text { recommendation for or against the use of the clinical action; } \\
\text { however, other factors may influence decision-making. }\end{array}$ \\
\hline D & There is fair evidence to recommend against the clinical action. \\
\hline $\mathrm{E}$ & $\begin{array}{l}\text { There is good evidence to recommend against the clinical } \\
\text { action. }\end{array}$ \\
\hline I & $\begin{array}{l}\text { There is insufficient evidence (in terms of quantity or quality or } \\
\text { both) to make a recommendation; however, other factors may } \\
\text { influence decision-making. }\end{array}$ \\
\hline \multicolumn{2}{|l|}{$\begin{array}{l}\text { Level of } \\
\text { evidence }\end{array}$} \\
\hline I & Evidence from one or more randomized controlled trials. \\
\hline II-1 & Evidence from nonrandomized controlled trials. \\
\hline II-2 & $\begin{array}{l}\text { Evidence from cohort or case-control studies, preferably from } \\
\text { more than one centre or research group. }\end{array}$ \\
\hline II-3 & $\begin{array}{l}\text { Evidence from comparisons between times or places, with or } \\
\text { without the intervention; dramatic results from uncontrolled } \\
\text { experiments may be included. }\end{array}$ \\
\hline III & $\begin{array}{l}\text { Opinions of respected authorities, based on clinical experience; } \\
\text { descriptive studies or reports of expert committees. }\end{array}$ \\
\hline
\end{tabular}

*Modified from the Canadian Task Force on Preventive Health Care. ${ }^{20}$

†The strongest recommendations (grades $A$ and $E$ ) are reserved for interventions whose value is

supported or highly negated by level I evidence. Grade B and D recommendations are associated with

level II-1 and level II-2 evidence. Grade I recommendations reflect level II-3 and level III evidence and

indicate that existing evidence is of insufficient quality or quantity (or both) to support a specific

recommendation. review encompasses records published in or added to the register between 2005 and June 2008.

We also reviewed several asthma guidelines, specifically the Canadian consensus guidelines of $1999^{13}$ and $2003,{ }^{14}$ the 2008 British Thoracic Society - Scottish Intercollegiate Guidelines Network guidelines, ${ }^{15}$ the American College of Chest Physicians' cough guidelines, ${ }^{16}$ the National Heart, Lung, and Blood Institute guidelines ${ }^{17}$ and the 2007 and 2008 guidelines of the Global Initiative for Asthma. ${ }^{18,19}$ The recent Global Initiative for Asthma guidelines were given the most credence because they are the most recent international guideavailable and because several Canadian respirologists eaders in the guideline-creation process. Furthermore, MEDLINE and PubMed for articles on newe (he diagnosis of asthma. Finally, we took into account our own clinical experience, as supported by the relnt referenced evidence.

We based our grades of evidence on those of the Canadian Task Force on Preventive Health Care (Table 1). ${ }^{20}$

\section{Approach to asthma diagnosis}

Asthma should be suspected in patients with recurrent respiratory symptoms, particularly cough, wheeze, chest tightness and dyspnea. Alternative diagnoses should be excluded. An objective lung function test such as spirometry can be used to confirm airway obstruction and to demonstrate reversibility of obstruction with bronchodilator medication.

\section{History}

The clinical features associated with asthma are listed in Box 1. If the history is strongly suggestive of asthma, then a trial of treatment is warranted. If the trial is successful, asthma treatment should be continued. ${ }^{15}$ Objective testing to confirm the diagnosis should be considered at a later date. If the treatment is unsuccessful, or if the history is less clearly suggestive of asthma, objective testing should be performed to confirm the diagnosis. If the spirometry results are normal in such patients, further objective confirmation of asthma by measurement of airway responsiveness will validate the presence of current asthma, although it does not exclude past or future asthma. Alternative causes of symptoms suggestive of asthma (Box 2) should also be considered in the differential diagnosis of asthma.

Dyspnea can have respiratory, cardiac, hematologic, neuromuscular or psychosomatic causes, but the pattern of symptoms associated with this problem 
Box 1: Clinical features related to probability of asthma in those with episodic symptoms*

Features favouring primary diagnosis of asthma

- At least 2 of the following symptoms: wheeze, breathlessness, chest tightness or cough with or without sputum, especially:

- if symptoms are worse at night and early in the morning

- if symptoms occur in response to exercise, exposure to allergens or exposure to cold air

- if symptoms occur after taking ASA or B-blockers

- History of atopic disorder

- Findings of widespread wheeze on auscultation

- Low FEV F $_{1}$ or peak expiratory flow (current or historical) that is otherwise unexplained

- Peripheral blood eosinophilia that is otherwise unexplained

Features not favouring primary diagnosis of asthma

- Prominent dizziness, light-headedness or peripheral tingling (in the absence of wheeze)

- Chronic productive cough in the absence of wheeze or breathlessness

- Normal results on physical examination of the chest during symptomatic episodes

- Voice disturbance

- Symptoms only with colds

- Significant smoking history (more than 20 pack-years)

- Cardiac disease

- Normal peak expiratory flow or spirometry results during symptomatic episodes (not an exclusion criterion)

Note: ASA = acetylsalicylic acid, $\mathrm{FEV}_{1}=$ forced expiratory volume in 1 second *Amended from British Guideline on the Management of Asthma: A National Clinical Guideline. ${ }^{15}$

may point to the specific diagnosis (Box 1). Distinguishing asthma from chronic obstructive pulmonary disease (COPD) is a common clinical challenge. Asthma is associated with variable symptoms that often worsen after exposure to triggers and with nocturnal symptoms (usually occurring between 2 am and $6 \mathrm{am}$ ). In contrast, patients with COPD tend to experience a gradual increase in symptoms over time, with exacerbations often being related to infectious precipitants (Table 2). ${ }^{22}$ Also, COPD is characterized by irreversible or only partially reversible airflow obstruction and results from an abnormal inflammatory response to noxious agents. Asthma and COPD can coexist, particularly in people who smoke. ${ }^{19,23}$ Validated symptom-based questionnaires and diagnostic algorithms, designed for use in countries without the capabilities to objectively measure lung function, can be used to differentiate these conditions. ${ }^{12}$

Congestive heart failure may feature symptoms similar to those of asthma, including cough and breathlessness. However, heart failure most commonly occurs in patients with a known history of cardiac problems and is often associated with ankle edema and weight gain. Moreover, although nocturnal symptoms are often prominent in heart failure, they tend to occur 1 or 2 hours after the patient reclines, rather than in the early morning hours.
Box 2: Alternative causes of symptoms suggestive of asthma*

- Other obstructive lung diseases

- Chronic obstructive pulmonary disease

- Eosinophilic bronchitis

- Bronchiectasis

- Cystic fibrosis

- Primary ciliary dyskinesia syndrome

- Immunoglobulin deficiency

- Bronchopulmonary dysplasia

- Chronic rhinosinusitis

- Gastroesophageal reflux

- Hyperventilation syndrome and panic attacks

- Vocal cord dysfunction ${ }^{21}$

- Infections:

- Recurrent viral infections of the lower respiratory tract

- Tuberculosis

- Other respiratory infections (e.g., chronic fungal, mycobacterial or parasitic infections)

- Mechanical obstruction of the airways:

- Tumour (benign or malignant)

- Foreign-body aspiration

- Congenital malformations of the airways

- Upper airway obstruction

- Medications (e.g., angiotensin-converting-enzyme inhibitors)

- Nonobstructive lung diseases (e.g., diffuse parenchymal lung disease, pulmonary embolism)

- Extrapulmonary diseases (e.g., left ventricular failure, congenital heart disease)

*Based on the National Asthma Education and Prevention Program ${ }^{17}$ and the Global Initiative for Asthma. ${ }^{18}$

The classic symptoms of asthma are listed in Box 1. It is important to elicit the possible triggers of asthma symptoms, especially those that can be modified. These triggers are typically allergic but may be occupational in nature and are commonly overlooked unless specifically considered. If workrelated asthma is a possibility, details of work exposures and a pattern of improvement of asthma symptoms during holidays should be explored.

Comorbidities that can aggravate asthma, such as allergic rhinitis and gastroesophageal reflux disease, should also be documented.

Asthma is 1 of the 3 main causes of chronic cough in patients with normal results on chest radiography who are not taking angiotensin-converting-enzyme inhibitors (the others being rhinosinusitis and gastroesophageal reflux disease). Cough due to asthma usually occurs at night, and hence evaluations during the day may be normal. ${ }^{24}$ In patients with a persistent cough, asthma can be diagnosed in the same manner as for those who present with dyspnea or wheeze. ${ }^{17,18}$

\section{Physical examination}

The physical examination is relatively insensitive for diagnosis of asthma. Between episodes of asthma activity, physical 
signs of asthma may be absent, and the results of a physical examination are often entirely normal. Thus, the absence of physical findings does not rule out asthma. For this reason, an accurate, focused history combined with objective testing is essential.

The clinician should, however, look for signs of asthma such as wheeze, a prolonged expiratory phase and use of accessory muscles. Findings on the skin (i.e., eczema) and in the upper respiratory tract (i.e., nasal congestion, nasal polyps or postnasal drip) may also relate to asthma.

The sound of an expiratory wheeze is identical in asthma, COPD, congestive heart failure and pneumonia and cannot be used to distinguish among these conditions. The presence of pulsus paradoxus is a potential marker of the severity of airflow obstruction during an exacerbation, but it is nonspecific in differentiating the causes of respiratory symptoms. ${ }^{25}$

Tracheal deviation, accompanied by unilateral hyperresonance to percussion, suggests the alternative diagnosis of pneumothorax. Jugular venous distension suggests congestive heart failure or pericardial effusion. Clubbing, which is not associated with asthma, suggests an alternative diagnosis such as bronchiectasis, interstitial lung disease or malignant disease. ${ }^{26}$

\section{Definitive diagnosis of asthma}

The diagnosis of asthma requires a history or current presence of respiratory signs and symptoms consistent with asthma (Box 1), combined with the objective demonstration of variable airflow obstruction. Variable airflow obstruction means that the obstruction is not necessarily present at all times, varying with time, exposure to asthma triggers and treatment. A good response to asthma treatment in a patient with a typical history of asthma supports a diagnosis of asthma. ${ }^{1}$ However, objective confirmation of the variable airflow obstruction characteristic of asthma, using spirometry or peak expiratory flow monitoring, is required, especially for patients whose response to treatment is suboptimal or whose symptoms are not highly suggestive of asthma. ${ }^{9,19,25-29}$
Spirometry is recommended for all patients to confirm the diagnosis of asthma before initiation of possibly lifelong therapy. This form of objective testing is preferred over peak flow measurement because of the wide variation in predicted values for peak flow rates (as described below). Diagnosis is consequently less accurate if it is based on peak flow monitoring or a trial of therapy. Unfortunately, many clinicians diagnose asthma without confirming the diagnosis with objective testing, and misdiagnosis and mistreatment, particularly overtreatment, are therefore common. ${ }^{27,30}$

Spirometry is commonly performed in pulmonary function laboratories, but can be performed efficiently in primary care offices as well. ${ }^{31}$ Portable hand-held spirometers allow screening for obstruction ${ }^{32}$ and may be more easily used for this purpose than laboratory-based spirometry equipment. Out-of-office spirometry may be more timeconsuming and hence less desirable for patients - and, because feedback is delayed, less desirable for physicians - than spirometry done in primary care practice ${ }^{33-36}$ and specialist practice. Wherever the spirometry is done, it must be performed according to the proper protocols. ${ }^{37}$ All spirometers should be standardized after manufacture ${ }^{38-41}$ and calibrated regularly.

Spirometry measures the forced vital capacity (FVC, the maximum volume of air that can be exhaled) and the $\mathrm{FEV}_{1}$, from which the $\mathrm{FEV}_{1} / \mathrm{FVC}$ ratio can be calculated. The patient is instructed to take in as big a breath as possible, to seal his or her lips around the mouthpiece of the spirometer and to blow the air out as fast and as fully as possible. This must be done with full effort and reproducibility. Videos illustrating the proper technique for spirometry measurement can be found at www.olapep.ca.

In the normal population, the $\mathrm{FEV}_{1} / \mathrm{FVC}$ ratio is usually greater than 0.80 and possibly greater than 0.90 in children. ${ }^{19}$ Any values less than these suggest airflow obstruction. ${ }^{19}$ The Canadian COPD guidelines stipulate that an $\mathrm{FEV}_{1} / \mathrm{FVC}$ ratio of less than 0.70 after administration of a bronchodilator identifies airway obstruction associated with COPD. ${ }^{42}$

Table 2: Differences between asthma and chronic obstructive pulmonary disease (COPD)*

\begin{tabular}{|c|c|c|}
\hline Characteristic & Asthma & COPD \\
\hline Age at onset & Usually $<40 \mathrm{yr}$ & Usually $>40 \mathrm{yr}$ \\
\hline Smoking history & Not causal, but worsens control & Usually $>10$ pack-years \\
\hline Sputum production & Infrequent & Common \\
\hline Allergies & Common & Infrequent \\
\hline Clinical symptoms & Intermittent and variable & Persistent and progressive \\
\hline Course of disease & Stable (with exacerbations) & Progressive worsening (with exacerbations) \\
\hline $\begin{array}{l}\text { Importance of } \\
\text { nonrespiratory comorbid } \\
\text { illnesses }\end{array}$ & Not usually important & Often important \\
\hline Spirometry results & Often normalize over time & $\begin{array}{l}\text { May improve, but do not normalize over } \\
\text { time }\end{array}$ \\
\hline Airway inflammation & Eosinophilic & Neutrophilic \\
\hline
\end{tabular}

*Adapted with permission from the Canadian Pharmacists Journal: 140[Suppl 3], 2007.22 
The presence of one of the following ${ }^{18}$ is required to confirm reversibility of airflow obstruction, which is the hallmark of asthma (Figure 1):

- an improvement in $\mathrm{FEV}_{1}$ of at least $12 \%$ and at least $200 \mathrm{~mL}^{19,43-45} 15-20$ minutes after administration of an inhaled rapid-acting $\beta_{2}$-agonist, or

- an improvement in $\mathrm{FEV}_{1}$ of at least $20 \%$ and at least $200 \mathrm{~mL}$ after 2 weeks of treatment with an anti-inflammatory agent such as an inhaled corticosteroid or a leukotriene receptor antagonist. $^{38}$

Clinicians must correlate the patient's history and the results of the physical examination with the pulmonary function test results to ensure that the diagnosis is accurate.

\section{Work-related asthma}

The diagnosis, management and prevention of work-related asthma have been addressed in a recent consensus statement ${ }^{46}$ endorsed by the Canadian Thoracic Society. Workrelated asthma includes occupational asthma (de novo asthma or recurrence of previously quiescent childhood asthma caused by conditions attributable to a work environment ${ }^{46}$ ) and work-exacerbated asthma (asthma that is triggered by workplace factors in people who have pre-existing or concurrent asthma ${ }^{46}$ ).

The diagnosis of occupational asthma should be considered in all cases of new adult-onset asthma or recurrence of childhood asthma. Occupational asthma can be due to a specific sensitizing agent at work and is similar to an allergic response. Less frequently, it can be due to an acute, high-level exposure to an irritant at work. Work-exacerbated asthma may occur when there is exposure to 1 or more triggers at work that can exacerbate or aggravate asthma (such as dusts, fumes, cold air or exercise).

Although a history of asthma symptoms that are worse at work and that improve when away from work is very sensitive for both occupational asthma and work-exacerbated asthma, it is not very specific. Therefore, except if the patient experiences only a transient exacerbation of symptoms at work, the relation of asthma to the work environment must be confirmed with objective tests.

Assessing the relation of asthma to work begins with a
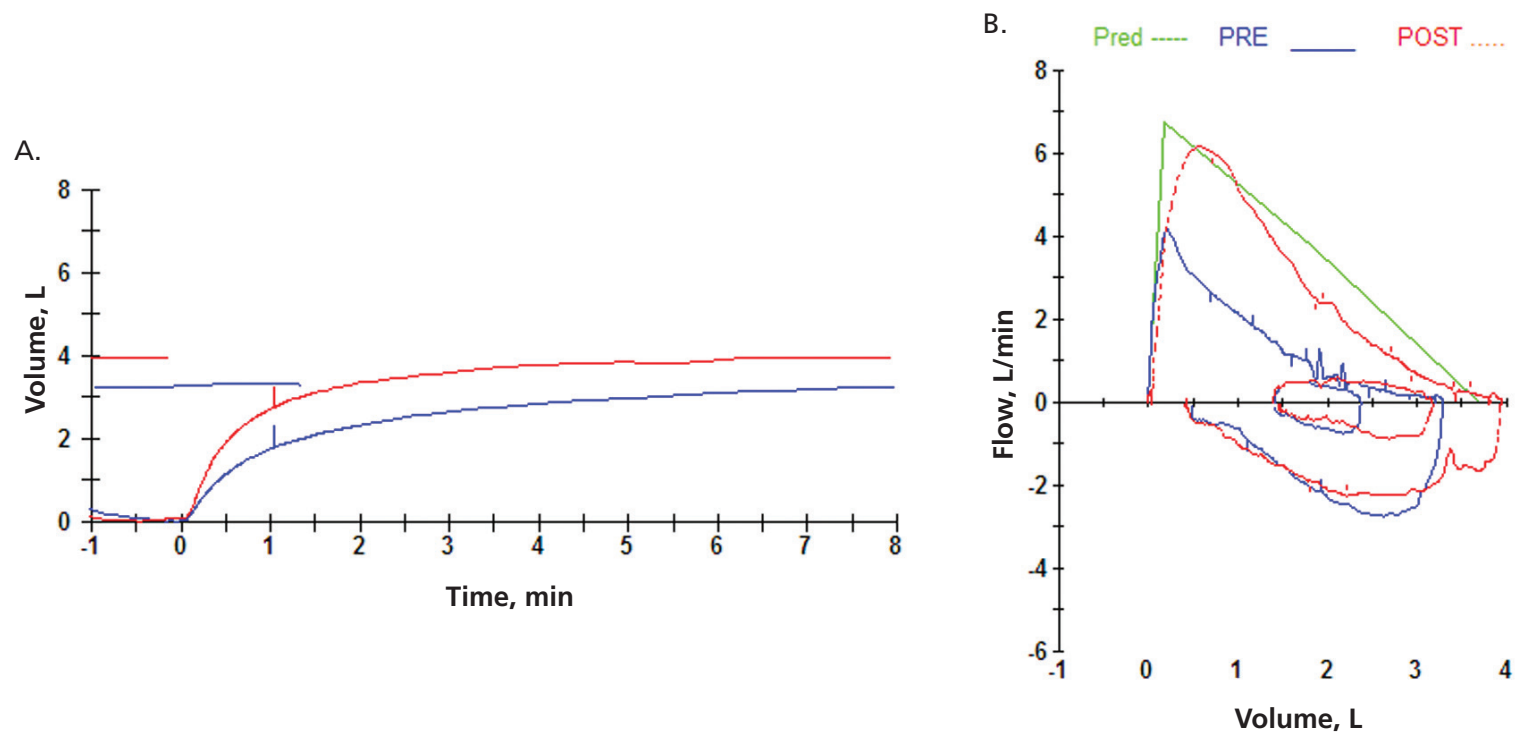

C.

\begin{tabular}{|c|c|c|c|c|c|c|}
\hline \multirow{2}{*}{$\begin{array}{l}\text { Spirometry } \\
\text { measure }\end{array}$} & \multirow[b]{2}{*}{ Predicted } & \multicolumn{2}{|c|}{ Before bronchodilator } & \multicolumn{2}{|c|}{ After bronchodilator } & \multirow[b]{2}{*}{$\%$ change } \\
\hline & & Best & $\%$ of predicted & Best & $\%$ of predicted & \\
\hline FVC, L & 3.70 & 3.30 & 89 & 3.95 & 107 & 20 \\
\hline $\mathrm{FEV}_{1}, \mathrm{~L}$ & 2.94 & 1.80 & 61 & 2.76 & 94 & 53 \\
\hline Ratio $\mathrm{FEV}_{1} / \mathrm{FVC}, \%$ & 80 & 55 & NA & 70 & NA & NA \\
\hline
\end{tabular}

Note: $\mathrm{FEV}_{1}=$ forced expiratory volume in 1 second, $\mathrm{FVC}=$ forced vital capacity, NA = not applicable

Figure 1: Spirometry results for a patient with asthma: volume-time curves (A), flow-volume loops (B) and data table (C). Obstruction is indicated by the ratio of forced expiratory volume in 1 second $\left(\mathrm{FEV}_{1}\right)$ to forced vital capacity $(55 \%)$; significant reversibility is indicated by the improvement in $\mathrm{FEV}_{1}$ after administration of bronchodilator $(0.96 \mathrm{~L}$ or $53 \%)$. These results are diagnostic for asthma. 


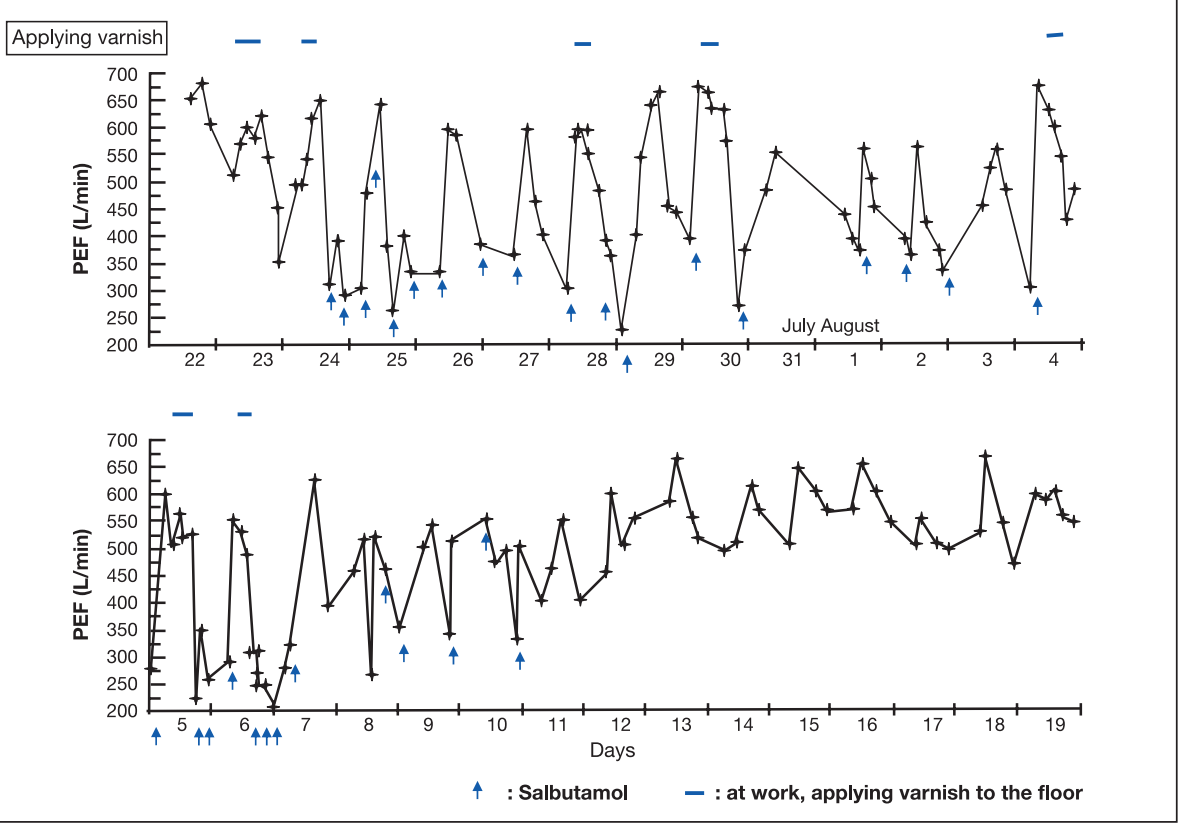

Figure 2: Serial recordings of peak expiratory flow (PEF) for a patient with occupational asthma. Measurements made during periods at work and while off work show objective improvement of PEF while off work, particularly after 3-4 days (see lower panel). The asthma was due to inhalation of toluene diisocyanate present in a varnish that the patient used at work (exposure indicated by horizontal bars at top of graph). Arrows indicate use of reliever medication (salbutamol) for asthma symptoms. Reproduced courtesy of Dr. André Cartier and Medical Resource Communications. ${ }^{47}$

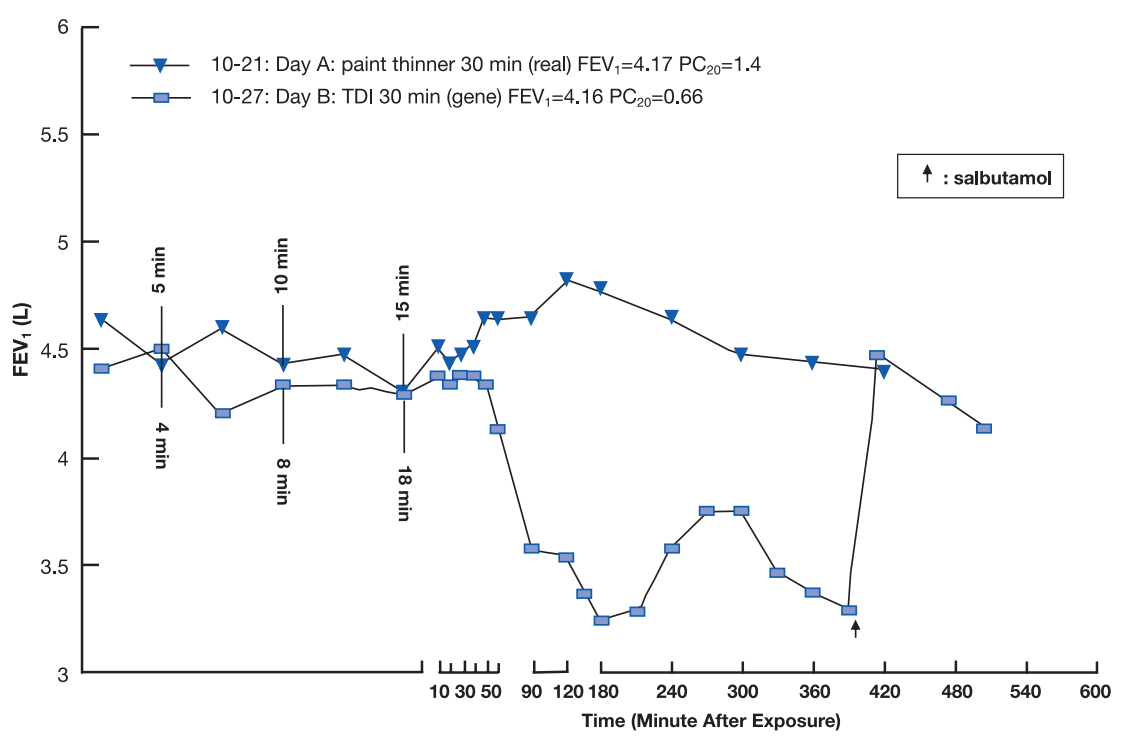

Figure 3: Bronchoprovocation challenge testing for occupational asthma for the same patient as depicted in Figure 2. The decrease in forced expiratory volume in 1 second $\left(\mathrm{FEV}_{1}\right)$ after a 30-minute exposure to toluene diisocyanate (TDI; day $\mathrm{B}$, October 27; rectangles) but not after a 30-minute control exposure to paint thinner (day A, October 21; triangles) indicates a positive result on this specific challenge test, providing further confirmation of the diagnosis of occupational asthma due to toluene diisocyanate. Testing was performed in a single-blind manner, with multiple spirometry measurements over time before and after exposure. For day $A$, $\mathrm{FEV}_{1}=4.17 \mathrm{~L}, \mathrm{PC}_{20}$ (concentration of the provoking agent that causes the FEV $\mathrm{F}_{1}$ to drop by $20 \%)=1.4$. For day $\mathrm{B}, \mathrm{FEV}_{1}=4.16 \mathrm{~L}_{,} \mathrm{PC}_{20}=0.66$. Arrow indicates use of reliever medication (salbutamol). Reproduced courtesy of Dr. André Cartier and Medical Resource Communications. ${ }^{47}$ thorough work history to determine exposures at work. Review of material safety data sheets from the workplace can assist in assessing exposure. Next, asthma should be objectively documented. As well, airway changes during periods at work compared with periods off work should be determined, by serial monitoring of peak expiratory flow at least 4 times a day for 2 weeks while the patient is working, then for a similar period when the patient is away from work (Figure 2). ${ }^{47}$ This monitoring is combined with a self-recorded diary of symptoms and use of reliever bronchodilator. ${ }^{43,44}$

As a more objective indicator, the presence of nonspecific bronchial hyperresponsiveness at the end of a working week, with improvement when the patient has been off work for 10 days or more, is supportive of occupational asthma. ${ }^{44,45}$ Only a few centres are able to perform bronchoprovocation challenges to specific work agents (Figure 3). ${ }^{44,46,48,49}$ Documentation of sensitization to a work agent (particularly high-molecular-weight agents such as flour, animal dander or urine) by skin prick tests or serum tests for specific immunoglobulin $\mathrm{E}$ antibodies may also help to confirm the diagnosis. In addition, sputum cell counts, although available in only a few centres, can be measured at work and away from work. The presence of sputum eosinophilia at work and its absence away from work provides strong supportive evidence for occupational asthma. ${ }^{50}$

Generally, as many of the above investigations as possible should be performed. This is because each test can be falsely negative or positive and also because there are often major implications for workplace conditions and compensation when a diagnosis of occupational asthma or frequent work-exacerbated asthma is made. Early referral to 
a specialist is recommended if work-related symptoms occur for more than a few days, because the tests can be difficult to interpret and hence the diagnosis can be more difficult to make if the patient has stopped working. Transient work-exacerbated asthma can usually be managed by the combination of reducing exposure and optimizing medication.

\section{Further testing when spirometry results are nondiagnostic}

If spirometry results are normal but the clinician still suspects the patient has asthma (a common situation, because asthma is a variable disease), the diagnosis can be confirmed by other objective tests. A diagnostic algorithm for asthma is shown in Figure 4.

\section{Serial peak flow monitoring}

Measurement of peak flow involves having the patient take in as deep a breath as possible and blow it out as hard and fast as possible into the measuring device (a peak flow meter). The test measures the fastest rate of expired airflow.

The following peak flow parameters support a diagnosis of asthma: ${ }^{19}$

- Diurnal variation in peak expiratory flow of more than $20 \%$ (or, with twice-daily readings, of more than $10 \%$ at each reading)

- An improvement of at least $60 \mathrm{~L} / \mathrm{min}$ or at least $20 \%$ after inhalation of a rapid-acting bronchodilator
Peak flow measurement is much simpler and cheaper than spirometry and can be used by patients for self-monitoring at home or in the workplace. However, unlike spirometers, peak flow meters do not measure flow rates over time, nor do they measure lung volumes. Furthermore, there is great variation in readings from peak flow meters and in their reference values. Hence, they are not highly reliable for either children or adults. ${ }^{18}$ Patient compliance with self-monitoring may also be an issue. Furthermore, peak expiratory flow is less sensitive to changes in airway calibre than is $\mathrm{FEV}_{1}$. Therefore, it is preferable to use peak flow meters only for monitoring asthma, not for diagnosis.

\section{Challenge testing}

If the clinical scenario suggests asthma but spirometry results are normal, the diagnosis of asthma can be confirmed with bronchoprovocation or challenge testing. The optimal type of challenge test to use depends on local availability and physician preference, and hence the choice is best left to an asthma specialist. The choices include direct challenges with histamine or methacholine ${ }^{51}$ and indirect airway challenges with mannitol or exercise..$^{52,53}$

Absolute and relative contraindications for challenge testing $^{53}$ are listed in Box 3. Challenge testing should be conducted in accordance with strict protocols in a laboratory or other facility equipped to manage acute bronchospasm. An initial spirometry test should be conducted to assess baseline $\mathrm{FEV}_{1}$ and safety to proceed. This initial measurement should also be used to determine reproducibility. Inability of the

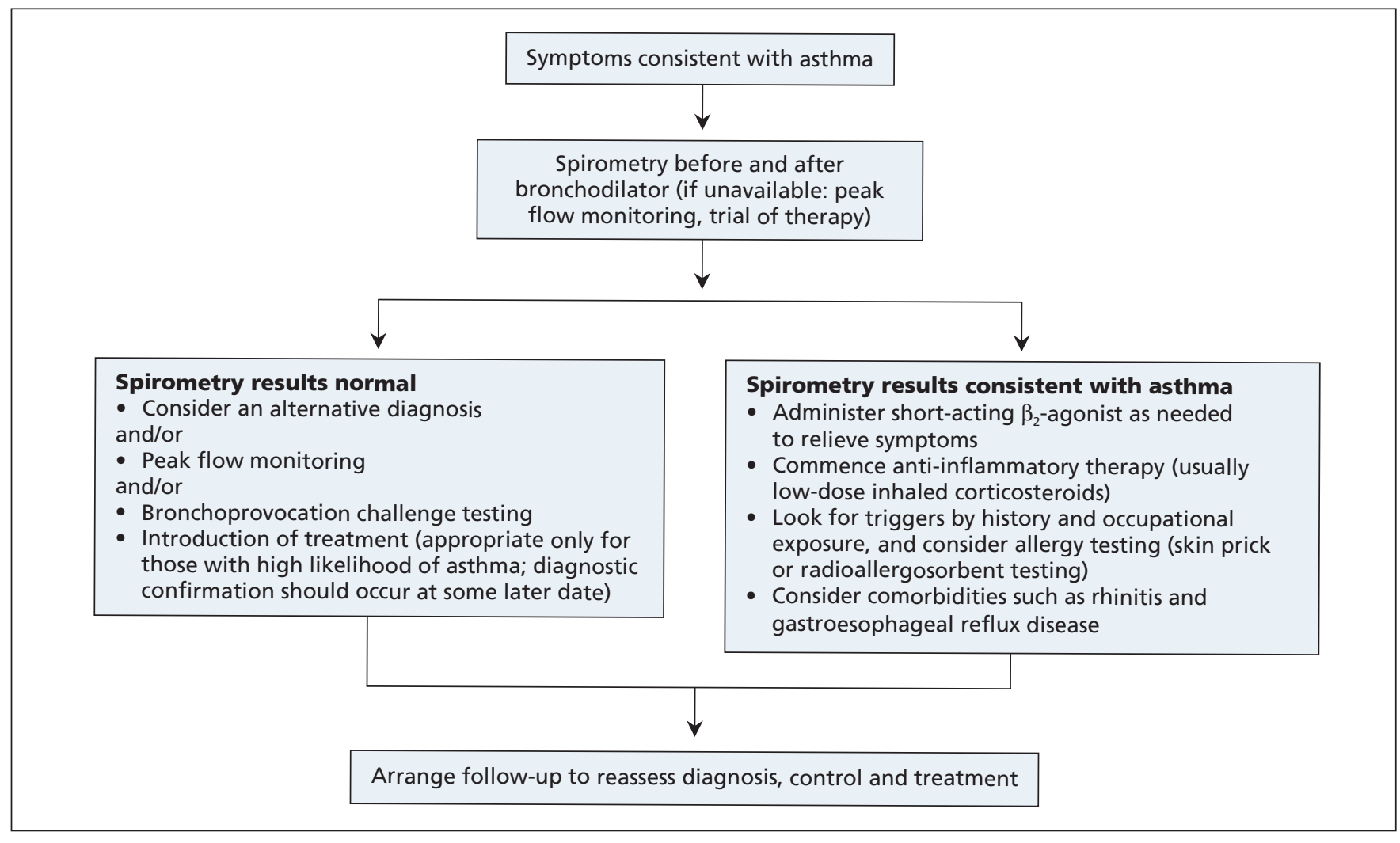

Figure 4: Diagnostic algorithm for asthma. 


\author{
Box 3: Contraindications to methacholine and exercise \\ challenge testing \\ Absolute contraindications \\ - Severe airflow limitation ( FEV $_{1}<1.0 \mathrm{~L}$ ) \\ - Heart attack or stroke in the past 3 months \\ - Uncontrolled hypertension, systolic blood pressure \\ $>200 \mathrm{~mm} \mathrm{Hg}$ or diastolic blood pressure $>100 \mathrm{~mm} \mathrm{Hg}$ \\ - Known aortic aneurysm \\ Relative contraindications \\ - Moderate airflow limitation $\left(\mathrm{FEV}_{1}<1.5 \mathrm{~L}\right)$ \\ - Inability to achieve spirometry results of acceptable quality \\ - Pregnancy \\ - Breastfeeding \\ - Current use of cholinesterase inhibitor medication \\ (for myasthenia gravis) \\ Note: $\mathrm{FEV}_{1}=$ forced expiratory volume in 1 second.
}

patient to generate reproducible flow-volume curves is often a reason to discontinue a bronchial provocation test. Challenge testing should also be reconsidered for patients whose $\mathrm{FEV}_{1}$ has been reduced to below $70 \%$ of the normal predicted value, as bronchoprovocation could cause significant bronchospasm in such individuals. ${ }^{19}$ To decrease the rate of false positive results, it may also be prudent to delay the test if the patient has just had an acute respiratory infection.

After completion of baseline spirometry, the inhalational challenge test begins with inhalation of saline, after which $\mathrm{FEV}_{1}$ is again recorded. If there is no change, then progressively higher doses of the provoking agent (e.g., methacholine) are given according to protocol, until the $\mathrm{FEV}_{1}$ drops by $20 \%$ or the maximum test dose is reached. An inhaled $\beta_{2}$-agonist is then provided to reverse the obstruction.

Airway reactivity is measured in terms of the dose or concentration of the provoking agent that causes the $\mathrm{FEV}_{1}$ to drop by $20 \%$ (the $\mathrm{PD}_{20}$ or $\mathrm{PC}_{20}$, respectively). For methacholine, a $\mathrm{PC}_{20}$ value lower than the standard threshold of $8 \mathrm{mg} / \mathrm{mL}$ is considered a positive result indicative of airway hyperreactivity.

A negative result on an inhalational challenge test in a patient who is symptomatic, in the absence of corticosteroid anti-inflammatory treatment and during a time when asthma triggers are still present, is highly sensitive in ruling out asthma. ${ }^{54,55}$ An exception is patients whose only trigger for bronchospasm is exercise, including elite athletes, in whom such results may be false negatives. However a positive test result does not always mean that asthma is present. Positive results may occur with allergic rhinitis, ${ }^{56}$ cystic fibrosis, ${ }^{57}$ bronchiectasis and COPD. ${ }^{56}$ As such, the challenge test, when negative, may be most useful in ruling out asthma.

An exercise challenge test measures the $\mathrm{FEV}_{1}$ or peak expiratory flow at rest and then again after exercise such as running on a treadmill or riding a stationary bike. Exerciseinduced bronchospasm is confirmed by a $15 \%$ or greater decrease in peak flow rate or $\mathrm{FEV}_{1}$. It may be further graded as mild (15\%-25\% decrease), moderate (25\%-40\% decrease) or severe $\left(40 \%\right.$ or greater decrease).$^{58}$ Exercise challenge is performed less frequently than methacholine challenge. This is primarily because the latter is easier to perform and more sensitive, although it is also less specific.

\section{Ancillary tests}

Chest radiography is not necessary for the diagnosis of obstructive airway disease, ${ }^{18}$ but it can help rule out other conditions such as congestive heart failure, lung cancer and bronchiectasis. Chest radiography should also be ordered in atypical cases ${ }^{15}$ or for patients with no response to asthma therapy.

Any relevant environmental allergies suggested by the history should be confirmed by skin prick tests with common allergen extracts or with specific immunoglobulin $\mathrm{E}$ allergen assays. ${ }^{59}$ Appropriate avoidance strategies can then be advocated. Examples of avoidance strategies are removal of pets; use of covers for mattresses, box spring, pillows and bedding; reduction of humidity (to kill house dust mites); and closing of windows during pollen seasons.

\section{Gaps in knowledge and future directions}

Other testing approaches may be part of future algorithms. Measurement of inflammatory markers such as sputum eosinophils or exhaled nitric oxide is already being used in some settings to evaluate asthma control and formulate management decisions. However, although such tests show clinical promise, they have not yet been rigorously investigated for use in the diagnosis of asthma ${ }^{60-62}$ and are currently limited to tertiary care centres and research facilities.

Tests to assess airway hyperresponsiveness with indirect stimuli - which induce the release of mediators from inflammatory cells and sensory nerves, causing contraction of bronchial smooth muscle and narrowing of the airways - are gaining attention for both identifying and monitoring asthma. Indirect stimuli include hyperpnea, hypertonic aerosols, osmotic challenges and adenosine monophosphate. Tests using indirect stimuli may be superior to those using direct stimuli, as responses to indirect challenges appear to be related to mast cells and eosinophils in the airways. Thus, indirect stimuli may better reflect the inflammatory status of the airway following treatment with inhaled corticosteroids. Also, the severity of airway hyperresponsiveness in response to an indirect stimulus is not closely related to baseline lung function. Many people with asthma who have normal lung function are very responsive to indirect stimuli. Moreover, osmotic challenge tests with mannitol have demonstrated higher specificity and greater safety for the diagnosis of asthma than traditional measures of airway hyperresponsiveness, such as methacholine challenge. ${ }^{63}$

A $10 \%$ or more fall in $\mathrm{FEV}_{1}$ from baseline is considered an abnormal response following hyperventilation with dry air, as is a fall of $15 \%$ from baseline following challenge with hypertonic aerosols. For adenosine monophosphate, a $20 \%$ or greater fall in $\mathrm{FEV}_{1}$ at a concentration of less than $400 \mathrm{mg} / \mathrm{mL}$ is considered abnormal. Furthermore, a positive response to bronchial provocation by eucapnic voluntary hyperventilation is considered acceptable confirmation of exercise-induced 


\section{Box 4: Key messages for the diagnosis of asthma}

\section{in adults}

- The diagnosis of asthma should be suspected in patients with recurrent cough, wheeze and dyspnea in whom no alternative diagnosis can be found and should be confirmed by an objective measurement of lung function or, if normal, by tests for bronchial hyperresponsiveness (grade A recommendation; level II-2 evidence).

- A clinical diagnosis of asthma should be prompted by symptoms such as episodic breathlessness, wheezing, cough, sputum and chest tightness (grade A recommendation; level II-2 evidence).

- Measurements of lung function by spirometry or peak expiratory flow provide an assessment of the severity of airflow limitation, its reversibility and its variability, and can be used to confirm the diagnosis of asthma (grade B recommendation; level II-2 evidence).

- Measurements of allergic status can help to identify risk factors that cause asthma symptoms in individual patients (grade B recommendation; level III evidence).

- Because the obstruction observed in asthma is variable, it is possible (and perhaps even likely) for the spirometry results to be normal for a patient who has asthma. Options to confirm asthma include bronchial challenge tests, serial peak flow monitoring and measurements of inflammation (grade B recommendation; level II-2 evidence).

- For patients with symptoms consistent with asthma who have normal lung function, measurement of airway responsiveness may help to establish the diagnosis (grade $B$ recommendation; level II-2 evidence).

- Challenge testing is potentially useful in patients with typical symptoms but normal spirometry results or atypical symptoms or possible occupational asthma (grade B recommendation; level III evidence).

asthma; ${ }^{64-66}$ it is in fact the current standard of the International Olympic Committee, although it is not often used in other settings.

Tests that use indirect stimuli differ from one another in their complexity and the amount of equipment required, many being possible only in a hospital laboratory. The use of eucapnic voluntary hyperventilation, for example, should be confined to specialist centres. However, a mannitol testing kit using a dry powder inhaler has recently been developed that could allow such testing to move outside the pulmonary function laboratory and into the office setting.

In the future, genetic testing may allow individually targeted diagnostics and therapeutic decisions..$^{67,68}$

\section{Case revisited}

Sara's history of childhood atopy and allergy, together with her persistent cough and wheeze, are suggestive of asthma. Her worsening of symptoms with physical activity and her upper respiratory tract infections also support a diagnosis of asthma. Moreover, the absence of heartburn makes a diagnosis of reflux less likely, ${ }^{69}$ and there is no clinical evidence of rhinitis. Although people with asthma may display many physical signs, normal results on physical examination, such as were found in Sara's case, are typical.
A careful environmental history is taken, covering both Sara's home and her workplace. Objective measurement of airflow obstruction and reversibility is required to confirm the diagnosis, and spirometry before and after administration of bronchodilator is ordered. Work-related asthma is suspected because her adult symptoms began while she was working and because she may be exposed to occupational sensitizers (such as diisocyanates or amines from autobody spray paints) and irritants in her workplace. Alternatively, she may be experiencing recurrence of childhood asthma, unrelated to her work but exacerbated by exposures at work, such as to fumes and dust. Therefore, if the diagnosis of asthma is confirmed, peak flow monitoring will be initiated and she will be referred to a specialist with expertise in work-related asthma.

In the interim, Sara is started on a fast-acting bronchodilator reliever medication, and she is instructed to use it on an as-needed basis to treat symptoms and before exertion to prevent symptoms. A controller medication (a steroid or combination steroid and long-acting bronchodilator inhaler ${ }^{70}$ ) is not prescribed until the diagnosis is confirmed.

Sara is encouraged to stop smoking: even a few minutes spent discussing smoking cessation can assist in changing a patient's behaviour. ${ }^{71,72}$ Follow-up is arranged for a time when the spirometry results will be available. If Sara's test results and clinical condition confirm persistent asthma, antiinflammatory therapy will be appropriate for her.

\section{Conclusions}

The key messages for the diagnosis of asthma in adults are presented in Box 4. Available tests can help the clinician to make a firm diagnosis of asthma in most patients. This common condition may well require lifelong therapy, and accurate diagnosis is therefore important. For people with a high likelihood of asthma and an appropriate response to therapy, a categorical diagnosis of asthma can be made. For such patients, confirmation with spirometry should be considered at a later date. For all others, spirometry should be part of the initial diagnostic work-up. Provocation testing may be necessary if the spirometry results are normal. The diagnosis of asthma depends on the physician's expert correlation of the patient's history, the results of a physical examination, the patient's clinical response and the results of pulmonary function testing.

\section{This article has been peer reviewed.}

Competing interests: Alan Kaplan has received honoraria for talks from AstraZeneca, GlaxoSmithKline, Nycomed, Boehringer Ingelheim and Pfizer. $\mathrm{He}$ has served on advisory boards for Merck Frosst, Nycomed, AstraZeneca and Boehringer Ingelheim. He has received travel reimbursement to meetings of the European Respiratory Society from Merck and AstraZeneca. Meyer Balter serves on advisory boards for AstraZeneca, Boehringer Ingelheim, GlaxoSmithKline, Merck, Nycomed and Pfizer and has received honoraria from each of these companies for speaking engagements. Alan Bell has been a member of AstraZeneca Canada's National Advisory Board for Respiratory Medicine from 2003 to the present and has received travel reimbursement to attend meetings of this board. He has also received consulting contracts and speaker fees from this board. He has received compensation for conducting clinical trials in respiratory disease from the following companies: AstraZeneca Canada, Nycomed Canada and Boehringer Ingelheim Canada. Harold Kim has received speakers fees and has served on advisory boards for 
Merck, GlaxoSmithKline, AstraZeneca, Graceway and Nycomed. Andrew McIvor has attended advisory board meetings and provided continuing medical education for which he has received honoraria from pharmaceutical companies involved in asthma management: AstraZeneca, Boehringer Ingelheim, Graceway, GlaxoSmithKline, Novartis, Merck Frosst and Pfizer.

Contributors: All authors contributed to the development, writing and editing of the article, and all approved the final version submitted for publication.

Acknowledgements: We thank the following individuals for their contributions to this article: Dr. Susan Tarlo, University of Toronto, Dr. Don Cockroft, University of Saskatchewan, and Dr. André Cartier and Dr. Catherine Lemiere, Université de Montréal for help with the section on occupational asthma; Dr. John Brannan, for help with mannitol testing; and Rosemary Frei, for assistance with literature searches and for editorial input.

Funding: The Canadian Thoracic Society has received funding to facilitate the knowledge translation activities of the CTS Asthma Committee from AstraZeneca Canada, GlaxoSmithKline Inc., Merck Frosst Canada and Novartis Pharmaceuticals. None of the sponsors played a role in the collection, review, analysis or interpretation of the scientific literature or in any decisions regarding the key messages presented in the case studies.

\section{REFERENCES}

1. Aaron SD, Vandemheen KL, Boulet LP, et al. Overdiagnosis of asthma in obese and nonobese adults. CMAJ 2008;179:1121-31.

2. Stanbrook MB, Kaplan A. The error of not measuring asthma. CMAJ 2008;179:1099-102.

3. Life and breath: respiratory disease in Canada. Ottawa (ON): Public Health Agency of Canada; 2007. Available: www.phac-aspc.gc.ca/publicat/2007/lbrdc -vsmrc/index-eng.php (accessed 2009 Jul. 24).

4. Kaplan A. Systems for the management of respiratory disease in primary care an international series: Canada. Prim Care Respir J 2008:17:73-8.

5. Persons with asthma, by age and sex (1996/1997-2005). Ottawa (ON): Statistics Canada; 2009. Available: www40.statcan.ca/101/cst01/health49a.htm (accessed 2009 Jan. 3)

6. FitzGerald JM, Boulet LP, McIvor A, et al. Asthma control in Canada remains suboptimal: The Reality of Asthma Control (TRAC) study. Can Respir J 2006;13 253-9.

7. Chapman KR, Ernst P, Grenville A. Control of asthma in Canada: patient and physician perspective. Am J Respir Crit Care Med 2000;161(Suppl):A799.

8. Krahn MD, Berka C, Langlois P, et al. Direct and indirect costs of asthma in Canada, 1990. CMAJ 1996;154:821-31.

9. Cowie RL, Underwood M, Field SK. Asthma symptoms do not predict spirometry. Can Respir J 2007;14:339-42

10. Parameswaran K, Pizzichini E, Pizzichini MMM, et al. Clinical judgement of airway inflammation versus sputum cell counts in patients with asthma. Eur Respir J 2000; $15: 486-90$

11. Lemiere C. Induced sputum and exhaled nitric oxide as non-invasive markers of airway inflammation from work exposures. Curr Opin Allergy Clin Immunol 2007:7:133-7

12. International Primary Care Respiratory Group. IPCRG guidelines for the management of chronic respiratory diseases in primary care. Prim Care Resp J 2006;1:1-74. Available: www.thepcrj.org/journ/guidelines.php (accessed 2009 Jan. 3).

13. Boulet L-P, Becker A, Bérubé D, et al. Canadian asthma consensus report, 1999. CMAJ 1999;161(11 Suppl 1):S1-62. Available: www.cmaj.ca/cgi/reprint/161 /11_suppl_1/s1 (accessed 2009 Jul. 24).

14. Lemiere C, Bai T, Balter M, et al. Adult asthma consensus guidelines update 2003 . Can Respir J 2004;11(Suppl A):9A-18A

15. British Thoracic Society; Scottish Intercollegiate Guidelines Network. British guideline on the management of asthma: a national clinical guideline. London (UK): The Society; 2008. Available: www.sign.ac.uk/pdf/sign101.pdf (accessed 2009 Jan. 3).

16. Irwin RS, Baumann MH, Bolser DC, et al. Diagnosis and management of cough executive summary: ACCP evidence-based clinical practice guidelines. Chest 2006;129 (Suppl 1):1S-23S

17. National Asthma Education and Prevention Program. Expert Panel report 3: Guidelines for the diagnosis and management of asthma. Full report 2007. Bethesda (MD): US Department of Health and Human Services, National Institutes of Health, National Heart, Lung, and Blood Institute; 2007. Available: www.nhlbi.nih.gov/guidelines/asthma/asthgdln.pdf (accessed 2009 Jan. 3).

18. Global strategy for asthma management and prevention. Global Initiative for Asthma; 2007. Available: www.ginasthma.org/Guidelineitem.asp??11=2\&12=1 \&intId=60 (accessed 2009 Jan. 3).

19. Bateman ED, Hurd SS, Barnes PJ, et al. Global strategy for asthma management and prevention: GINA executive summary. Eur Respir J 2008;31:143-78.

20. Canadian Task Force on Preventive Health Care. New grades for recommendations from the Canadian Task Force on Preventive Health Care. CMAJ 2003;169:207-8.

21. Gjevre JA, Hurst TS, Taylor-Gjevre RM, et al. The American Thoracic Society's spirometric criteria alone is inadequate in asthma diagnosis. Can Respir J 2006;13:433-7.

22. Hodder R. Clinical differences between asthma and chronic obstructive pulmonary disease (COPD). Can Pharm J 2007;140(Suppl 3):S8.

23. Jenkins CR, Thompson PJ, Gibson PG, et al. Distinguishing asthma and chronic obstructive pulmonary disease: Why, why not and how? Med J Aust 2005;183 (Suppl 1):S35-7.

24. Corrao WM, Braman SS, Irwin RS. Chronic cough as the sole presenting manifestation of bronchial asthma. N Engl J Med 1979;300:633-7.

25. Arnold DH, Gebretsadik T, Minton PA, et al. Clinical measures associated with $\mathrm{FEV}_{1}$ in persons with asthma requiring hospital admission. Am J Emerg Med 2007; $25: 425-9$.

26. Li JT, Pearlman DS, Nicklas RA, et al. Algorithm for the diagnosis and management of asthma: a practice parameter update: Joint Task Force on Practice Parameters, representing the American Academy of Allergy, Asthma and Immunology, the American College of Allergy, Asthma and Immunology, and the Joint Council of Allergy, Asthma and Immunology. Ann Allergy Asthma Immunol 1998;81:415-20.

27. Petty TL. Simple office spirometry. Clin Chest Med 2001;22:845-59.

28. Bellamy D. Spirometry in practice: a practical guide to using spirometry in primary care. 2nd ed. London (UK): The British Thoracic Society COPD Consortium; 2005. Available: www.brit-thoracic.org.uk/Portals/0/Clinical\%20Information/COPD /COPD\%20Consortium/spirometry_in_practice051.pdf (accessed 2009 Jan. 3).

29. National Asthma Education and Prevention Program. Expert Panel report: guidelines for the diagnosis and management of asthma update on selected topics2002. J Allergy Clin Immunol 2002;110 (Suppl 5):S141-219.

30. LindenSmith J, Morrison D, Deveau C, et al. Overdiagnosis of asthma in the community. Can Respir J 2004;11:111-6.

31. Tuomisto L, Jarvinen V, Laitinen J, et al. Asthma Programme in Finland: the quality of primary care spirometry is good. Prim Care Respir J 2008;17:226-31.

32. Rytila P, Helin T, Kinnula V. The use of microspirometry in detecting lowered FEV values in current or former smokers. Prim Care Respir J 2008;17:232-7.

33. Derom E, van Weel C, Liistro G, et al. Primary care spirometry. Eur Respir J 2008;31:197-203

34. Calverley P. Fulfilling the promise of primary care spirometry. Eur Respir $J$ 2008;31:8-10.

35. Pearson M, Ayres JG, Sarno M, et al. Diagnosis of airway obstruction in primary care in the UK: the CADRE (COPD and Asthma Diagnostic/managemen REassessment) programme 1997-2001. Int J Chron Obstruct Pulmon Dis 2006; $1: 435-43$

36. Hueto J, Cebollero P, Pascal I, et al. Spirometry in primary care in Navarre, Spain [article in Spanish]. Arch Bronconeumol 2006;42:326-31.

37. Miller MR, Hankinson J, Brusasco V, et al. ATS/ERS Task Force: Standardisation of lung function testing series. Number 2. Standardisation of spirometry. Eur Respir J 2005;26:319-38.

38. Pellegrino R, Viegi G, Brusasco V, et al. Interpretative strategies for lung function tests. Eur Respir J 2005;26:948-68.

39. American Thoracic Society. Standardization of spirometry, 1994 update. Am J Respir Crit Care Med 1995;152:1107-36.

40. Standardized lung function testing. Official statement of the European Respiratory Society. Eur Respir J Suppl 1993;16:1-100.

41. Sawyer G, Miles J, Lewis S, et al. Classification of asthma severity: Should the international guidelines be changed? Clin Exp Allergy 1998;28:1565-70.

42. O'Donnell DE, Hernandez P, Kaplan A, et al. Canadian Thoracic Society recommendations for management of chronic obstructive pulmonary disease - 2008 update - highlights for primary care. Can Respir J 2008;15(Suppl SA):1A-8A.

43. Beach J, Russell K, Blitz S, et al. Systematic review of the diagnosis of occupational asthma. Chest 2007;131:569-78.

44. Tarlo SM. Laboratory challenge testing for occupational asthma. J Allergy Clin Immunol 2003:111:692-4

45. Bright $\mathrm{P}$, Burge PS. Occupational lung disease. 8. The diagnosis of occupationa asthma from serial measurements of lung function at and away from work. Thorax 1996;51:857-63.

46. Tarlo SM, Balmes J, Balkissoon R, et al. Diagnosis and management of workrelated asthma: American College of Chest Physicians consensus statement. Chest 2008;134(3 Suppl):1S-41S Available: www.chestjournal.org/content/vol134/3 suppl/ (accessed 2009 Jan. 3).

47. Cartier A. What's new in respirology? Occupation asthma. Respiratum 2006;4

48. Tarlo SM, Liss GM. Occupational asthma: an approach to diagnosis and management. CMAJ 2003; 168:867-71.

49. Hoeppner VH, Murdock KY, Kooner S, et al. Severe acute "occupational asthma" caused by accidental allergen exposure in an allergen challenge laboratory. Ann Allergy 1985;55:36-7.

50. Girard F, Charboillez S, Cartier A, et al. An effective strategy for diagnosing occupational asthma: use of induced sputum. Am J Respir Crit Care Med 2004;170: $845-50$

51. Cockcroft DW. Bronchoprovocation methods: direct challenges. Clin Rev Allergy Immunol 2003;24:19-26.

52. Brannan JD, Anderson SD, Perry CP, et al. The safety and efficacy of inhaled dry powered mannitol as a bronchial provocation test for airway hyperresponsiveness: a phase 3 comparison study with hypertonic (4.5\%) saline. Respir Res 2005;6:144.

53. Crapo RO, Casaburi R, Coates AL, et al. Guidelines for methacholine and exercise challenge testing — 1999. This official statement of the American Thoracic Society was adopted by the ATS Board of Directors July 1999. Am J Respir Crit Care Med 2000;161:309-29. 
54. Boulet LP. Asymptomatic airway hyperresponsiveness: a curiosity or an opportunity to prevent asthma? Am J Respir Crit Care Med 2003;167:371-8.

55. Cockcroft DW, Murdock KY, Berscheid BA, et al. Sensitivity and specificity of histamine PC20 determination in a random selection of young college students. $J$ Allergy Clin Immunol 1992;89:23-30.

56. Ramsdale EH, Morris MM, Roberts RS, et al. Asymptomatic bronchial hyperresponsiveness in rhinitis. J Allergy Clin Immunol 1985;75:573-7.

57. van Haren EH, Lammers JW, Festen J, et al. The effects of the inhaled corticosteroid budesonide on lung function and bronchial hyperresponsiveness in adult patients with cystic fibrosis. Respir Med 1995;89:209-14.

58. Safran MR, McKeag D, Van Camp SP, editors. Manual of sports medicine Philadelphia (PA): Lippincott-Raven; 1998.

59. Douglass JA, O'Hehir RE. Diagnosis, treatment and prevention of allergic disease: the basics. Med J Aust 2006;185:228-33.

60. Hargreave FE. Quantitative sputum cell counts as a marker of airway inflammation in clinical practice. Curr Opin Allergy Clin Immunol 2007;7:102-6.59.

61. Parameswaran K, Pizzichini E, Pizzichini MMM, et al. Clinical judgement of airway inflammation versus sputum cell counts in patients with asthma. Eur Respir J 2000;15:486-90.

62. Lemiere C. Induced sputum and exhaled nitric oxide as non-invasive markers of airway inflammation from work exposures. Curr Opin Allergy Clin Immunol 2007; 7:133-7.

63. Brannan JD, Koskela H, Anderson SD. Monitoring asthma therapy using direct bronchial provocation tests. Clin Respir J 2007;1:3-15.

64. Spiering BA, Judelson DA, Rundell KW. An evaluation of standardizing target ventilation for eucapnic voluntary hyperventilation using $\mathrm{FEV}_{1}$. J Asthma 2004;41:745-9.

65. Haahtela T, Malmberg P, Moreira A. Mechanisms of asthma in Olympic athletes — practical implications. Allergy 2008;63:685-94.

66. Anderson SD, Argyros GJ, Magnussen H, et al. Provocation by eucapnic voluntary hyperpnoea to identify exercise induced bronchoconstriction. Br J Sports Med 2001;35:344-7.

67. Karjalainen J, Nieminen MM, Aromaa A, et al. The IL-1 $\beta$ genotype carries asthma susceptibility only in men. J Allergy Clin Immunol 2002;109:514-6.

68. Koppelman GH, te Meerman GJ, Postma DS. Genetic testing for asthma. Eur Respir J 2008; 32:775-82.

69. Irwin RS, French CL, Curley FJ, et al. Chronic cough due to gastroesophageal reflux. Clinical, diagnostic, and pathogenetic aspects. Chest 1993;104:1511-7.

70. Lemière C, Becker A, Boulet LP, et al. Should combination therapy with inhaled corticosteroids and long-acting $\beta_{2}$-agonists be prescribed as initial maintenance treatment for asthma? CMAJ 2002;167:1008-9.

71. Treating tobacco use and dependence: 2008 update. Washington (DC): US Department of Health and Human Services, Public Health Service; 2008. Available: www.surgeongeneral.gov/tobacco/treating_tobacco_use08.pdf (accessed 2009 Jan. 3).

72. Kaplan KE. Ten minute consultation: smoking cessation. BMJ 2008;336:217.

Correspondence to: Dr. Alan Kaplan, Chair, Family Physician Airways Group of Canada, 17 Bedford Park Ave., Richmond Hill ON L4C 2N9; fax 905 884-1195; For4kids@gmail.com

This article is the second in a 7-part case study series that was developed as a knowledge translation initiative of the Canadian Thoracic Society Asthma Committee. The series aims to educate and inform primary care providers and nonrespiratory specialists about the diagnosis and management of asthma. The key messages presented in the cases are not clinical practice guidelines but are based on a review of the most recent scientific evidence available. Financial support for the publication of this series has been provided, in part, by the Canadian Thoracic Society.

\section{Article to date in this series}

- Subbarao P, Mandhane PJ, Sears MR. Asthma: epidemiology, etiology and risk factors. CMAJ 2009. DOI:10.1503/cmaj.080612. 